\title{
Transcatheter patent ductus arteriosus closure: what have we learned after over 25 years? A single-center experience with 1036 patients
}

\author{
Michał Gałeczka1', Małgorzata Szkutnik¹, Jacek Białkowski', Linda Litwin'1, \\ Sebastian Smerdziński', Mateusz Knop ${ }^{1}$, Jan Głowacki², Roland Fiszer ${ }^{1}$ \\ 1 Department of Congenital Heart Defects and Pediatric Cardiology, Faculty of Medical Sciences in Zabrze, Medical University of Silesia, Silesian Center for Heart Diseases, Zabrze, Poland \\ 2 Department of Radiology and Radiodiagnostics, Faculty of Medical Sciences in Zabrze, Medical University of Silesia, Silesian Center for Heart Diseases, Zabrze, Poland
}

\section{KEY WORDS}

patent ductus arteriosus, percutaneous intervention, treatment outcome

Correspondence to: Michał Gałeczka, MD, Department of Congenital Heart Defects and Pediatric Cardiology, Faculty of Medical Sciences in Zabrze, Medical University of Silesia, Silesian Center for Heart Diseases, ul. Curie-Skłodowskiej 9, 41-800 Zabrze, Poland, phone: +48323733669 , email: michalgaleczka@gmail.com Received: August 9, 2020. Revision accepted: January 27, 2021. Published online: February 16, 2021. Kardiol Pol. 2021; 79 (3): 287-293 doi:10.33963/KP.15812 Copyright by the Author(s), 2021

\begin{abstract}
BACKGROUND Transcatheter patent ductus arteriosus (PDA) closure has become the first-choice method of treatment in the majority of patients. However, device selection poses a challenge.

AIMS This study aimed to analyze periprocedural and 1-year outcomes of PDA transcatheter closure performed with different devices throughout a 25-year time period in a single center.

METHODS All 1036 patients who underwent transcatheter PDA closure between 1993 and 2020 were included in retrospective analysis. Various devices were used: the Rashkind device (RD; $n=25)$, coils $(n=469)$, nitinol duct occluders type I (DO I; $n=300)$, type II $(n=32)$, type II additional sizes (ADO II AS; $n=209$ ), as well as off-label devices: vascular plugs and atrial septal and muscular ventricular septal defect occluders $(n=17)$. Data on 24 -hour and 1-year follow-up were available for $100 \%$ and $78.9 \%$ of the study patients, respectively.

RESULTS The procedure was successful in $98.6 \%$ of the study patients, with a major complication rate of $0.2 \%$. Complete PDA closure after a year was observed in $81.8 \%$ of the patients treated with RD, $93.7 \%$ of those with coils, and $100 \%$ of those with duct occluders. There were no differences between Amplatzer DO I $(n=159)$ and its DO I copies manufactured in China $(n=141)$ with regard to success, efficacy, and complication rates. Recently, ADO II AS has replaced coils and become the preferred device to close small-to-moderate PDA.
\end{abstract}

CONCLUSIONS Transcatheter PDA closure with all types of nitinol duct occluders is safe and effective, with no residual shunting at 1-year follow-up. Due to higher efficacy, ADO II AS has replaced coils in the treatment of smaller PDA.

INTRODUCTION Patent ductus arteriosus (PDA) is diagnosed more frequently nowadays owing to advancements in echocardiography and is considered to affect as much as $0.2 \%$ of the population. ' Since the first reports of PDA percutaneous closure with an Ivalon plug over 50 years ago, and later with a double-umbrella Rashkind device (RD; C. R. Bard, Ireland), there has been tremendous progress in implant development. ${ }^{2,3}$ Devices such as pushable and detachable coils, for example Flipper coils (Cook Medical, Limerick, Ireland), Amplatzer Duct Occluder type
I (DO I; AGA [now Abbott], Minneapolis, Minnesota, United States) - a prototype of nitinol-based, self-expanding occluder-and its successors, type II and type II Additional Sizes (ADO II and ADO II AS), as well as occasionally used off-label devices such as Amplatzer septal and muscular ventricular septal defect (VSD) occluders and Amplatzer vascular plugs, constitute a wide armamentarium for PDA percutaneous closure. ${ }^{4-11}$ To date, the transcatheter approach has gradually become the gold standard in PDA treatment in the majority of patients, and DO I and coils have 


\section{WHAT'S NEW?}

Transcatheter patent ductus arteriosus (PDA) closure has proven its safety and efficacy and become the first-choice method of treatment in the majority of patients; however, device selection remains an open question. Transcatheter PDA closure with all types of nitinol duct occluders is safe and effective, with no residual shunting reported at 1-year follow-up. Since the introduction of Amplatzer Duct Occluder II Additional Sizes, it has replaced coils and become the preferred device to close small-to-moderate PDA owing to high complete closure rates and fewer embolizations. Moreover, it can be applied in all age groups. Original Amplatzer Duct Occluder type I and Amplatzer-like copies provide comparable results in percutaneous closure of larger PDA. Despite the development of PDA closure devices, the use of off-label equipment is necessary and safe in selected patients.

been the most widely used devices for PDA closure so far. ${ }^{12}$ There have been numerous publications regarding the outcome of transcatheter PDA closure; however, after the introduction of multiple newer devices (such as ADO II and ADO II AS), the current comparative data on different implants and their application are scarce. ${ }^{13}$ The aim of this retrospective study was to analyze periprocedural and 1-year outcomes of transcatheter PDA closure with various devices throughout a 25-year time period in a single center.

METHODS Study population All 1036 consecutive patients who underwent attempted transcatheter closure of PDA between October 1993 and February 2020 in a single tertiary center were included in the retrospective, descriptive, and nonrandomized analysis. Medical records, hemodynamic data, echocardiographic findings, and follow-up data were obtained from our registry. There were no exclusion criteria regarding the analyzed population. The study was approved by the university research ethics committee. Written informed consent was obtained from all patients or their caregivers prior to the procedure. The indications for transcatheter versus surgical PDA closure changed over the investigated time period and depended mostly on the availability and development of the devices. Nineteen patients (1.8\%) were deemed eligible for the percutaneous procedure due to either residual shunt or recanalization of previously surgically closed PDA. ${ }^{14}$ The permanent contraindications to PDA treatment included Eisenmenger syndrome, a duct too large for endovascular treatment with available devices, preterm neonates, and a comorbidity requiring cardiac surgery.

Transcatheter procedure All procedures were performed under fluoroscopic guidance and general or local anesthesia in children and adults, respectively. After femoral artery only, or artery and vein, access completion (4-6 French sheath), intravenous heparin (50 IU/kg) and cefazolin were administered. The size and shape of PDA were assessed on both preprocedural transthoracic echocardiography and angiography in later$\mathrm{al}$ and / or right oblique projections. The PDA morphology was defined according to the Krichenko classification by angiography. ${ }^{15}$ In 15 patients (1.4\%), for better duct visualization, balloon static calibration was performed with an 18 - or a $24-\mathrm{mm}$ Amplatzer sizing balloons. In adult patients with mean pulmonary artery pressure (mPAP) greater than or equal to $50 \mathrm{~mm} \mathrm{Hg}$, the 10-minute balloon occlusion test was performed before PDA closure $(n=2)$. The following devices were used in a routine manner (described elsewhere ${ }^{3-7}$ ), depending on their availability, the operator's preferences, and PDA morphology: RD ( $\mathrm{n}=25)$, detachable coil(s) ( $\mathrm{n}=469$; multiple and sequentially in 18 patients), DO I ( $\mathrm{n}=300$; among them 159 Amplatzer and 141 Chinese copies: 63 Cardi-O-Fix, 37 Hyperion, 32 HeartR, and 9 Cera duct occluders), ADO II ( $\mathrm{n}=32)$, ADO II AS ( $\mathrm{n}=209)$, as well as off-label devices: atrial septal occluder (ASO; $\mathrm{n}=7$; among them 2 Amplatzer and 5 CardioSEAL/STARFlex devices), Amplatzer muscular VSD occluder ( $\mathrm{n}=6)$, Amplatzer Vascular Plug type II (AVP II; $n=4$ ) (see FIGURE1 for details). Overall, 1052 devices were used in 1033 patients; no occluder was used in 3 patients because of the duct size (too large) in a single person and difficulty to cross the duct with any guidewire in 2 patients. Patients were divided into groups depending on the device used. Off-label devices were excluded from the comparative analysis owing to the limited number of patients $(\mathrm{n} \leq 7)$. Although $\mathrm{RD}$ was withdrawn from clinical practice in 2000, it was not excluded from the comparison. The anterograde (venous) delivery approach was employed in 372 patients (36\%), the retrograde (arterial) approach in 652 (63.1\%), and both approaches (multiple coils) in 9 (0.9\%) (Supplementary material, Table S1). In 93 patients (9\%), an arteriovenous loop was necessary to deploy the device from the venous site. Devices were released after confirmation of a stable position by angiography. In selected patients, the PAP measurement was repeated. Embolization with subsequent device percutaneous and uneventful retrieval was classified as a minor complication but analyzed separately, as it was mostly related to the device type (RD, coils). Residual PDA leakage was evaluated by color Doppler echocardiography. Protrusion was defined as blood flow turbulence either in the descending aorta or in the pulmonary artery with a velocity exceeding $2 \mathrm{~m} / \mathrm{s}$ by Doppler echocardiography.

The follow-up echocardiographic assessment of implanted patients was conducted immediately after the procedure, after 24 hours, and then after 1 month, 6 months, and 12 months in an outpatient clinic according to a predetermined schedule. Data on 24-hour and 1-year follow-up were available for $100 \%$ and $78.9 \%$ of the patients, respectively. Despite the fact 


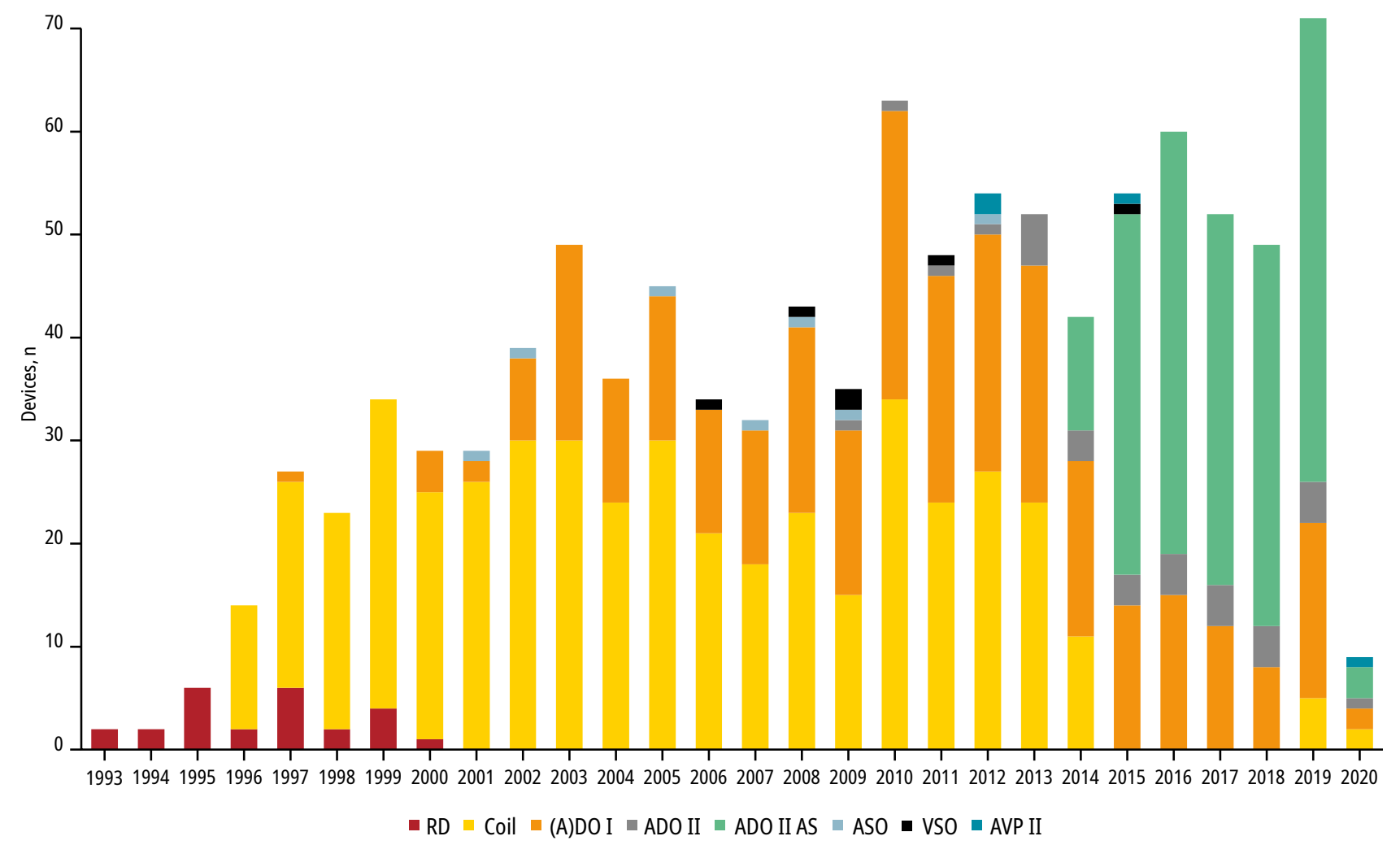

FIGURE 1 Number of various devices used for transcatheter closure of patent ductus arteriosus per year Abbreviations: (A)DO I, (Amplatzer) Duct Occluder type I; ADO II, Amplatzer Duct Occluder type II; ADO II AS, Amplatzer Duct Occluder type II Additional Sizes; ASO, atrial septal occluder; AVP II, Amplatzer Vascular Plug type II; RD, Rashkind device; VSO, muscular VSD occluder

that 36 patients (3.5\%) did not reach the 1-year follow-up point, they were included in the analysis because of complete PDA closure at 1-month follow-up.

Statistical analysis Statistical analyses were performed using the Statistica 13.3 software (StatSoft Polska, Kraków, Poland). All continuous variables were expressed as mean (SD) or median with range and interquartile range (IQR), as appropriate. Categorical data were presented as numbers (percentages). Data normality was verified using the Shapiro-Wilk test. Study groups were compared using the $t$ test, MannWhitney test, Fisher exact test, or Kruskal-Wallis test with post hoc pairwise comparison adjusted with the Bonferroni correction, as appropriate. The association between fluoroscopy time and the time period from the introduction of the transcatheter PDA closure procedure was examined using the Spearman correlation. A $P$ value less than 0.05 was considered significant.

RESULTS Baseline characteristics There were 672 women (64.9\%) and 364 men (35.1\%) included in the study, at a median age of 4 years (range, 2 months to 84.5 years; IQR, 2-10 years) and a median weight of $17 \mathrm{~kg}$ (range, $3.9-136 \mathrm{~kg}$;
IQR, 12.5-35 kg). Eleven patients (1.1\%) weighed less than $6 \mathrm{~kg}, 117$ (11.3\%) were adults (older than 18 years), and 36 (3.5\%) were older than 50 years (Supplementary material, Figure S1). On angiography, the PDA anatomy was classified as type A (conical) in 508 patients (49\%), type B (window-like, less than 3-mm long) in 25 (2.4\%), type C (tubular) in 55 (5.3\%), type D (complex) in 156 (15.1\%), and type E (elongated) in 273 (26.4\%). The median narrowest PDA diameter and length were $2 \mathrm{~mm}$ (range, $1-10 \mathrm{~mm}$; IQR, 1.5-2.5 mm) and $7 \mathrm{~mm}$ (range, 2-20 mm; IQR, 5-9 mm), respectively. Mean pulmonary artery pressure was greater than or equal to $25 \mathrm{~mm} \mathrm{Hg}$ in 167 patients (16.1\%).

Transcatheter procedure Differences between the study groups divided by the device used in terms of age, weight, and the narrowest PDA diameter were noted $(P=0.009, P=0.02$, and $P<0.001$, respectively) (FIGURE2). Among nitinol wire mesh duct occluders (DO I, ADO II, and ADO II AS), there were no differences regarding age or weight. Over time, trends towards PDA closure in younger patients and those with a lower body weight were observed. Patent ductus arteriosus type A, which was the most commonly seen lesion (49\%), was predominantly treated with DO I, especially in ducts with the narrowest 

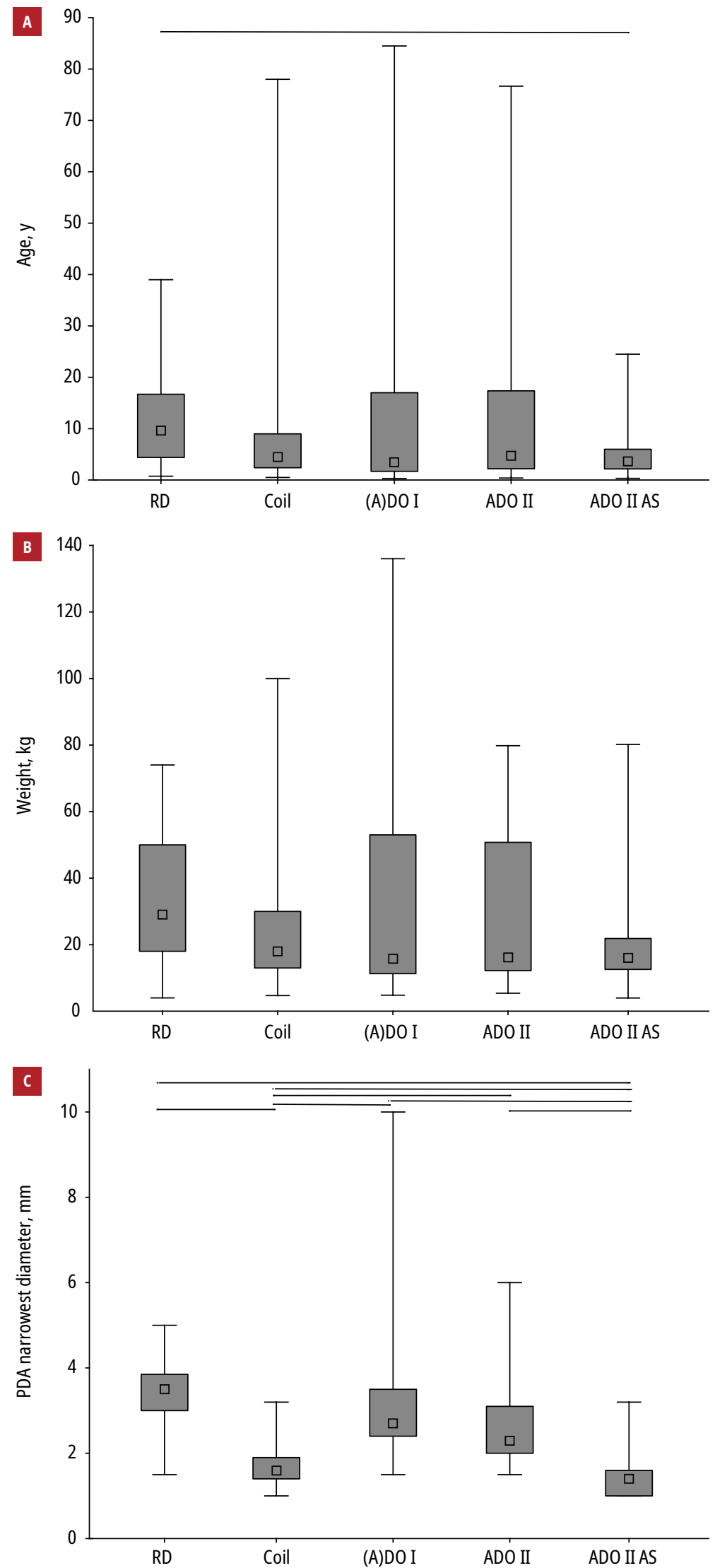

FIGURE 2 Differences in terms of age (in years; $P=0.009)(\mathbf{A})$, weight (in $\mathrm{kg} ; P=0.02)(\mathbf{B})$, and patent ductus arteriosus (PDA) narrowest diameter (in $\mathrm{mm} ; P<0.001)(\mathbf{C})$ in patients implanted with selected devices (whiskers denote minimum-maximum; gray boxes, interquartile range; and squares, the median value). Significant differences between the study groups in the post hoc test (with the Bonferroni correction) are indicated.

Abbreviations: see FIGURE 1 diameter exceeding $2.5 \mathrm{~mm}$. Smaller type A ducts were closed with coils, and after the introduction in 2014 to our clinical practice, with ADO II AS. The least frequent PDA type B was mostly treated with RD $(n=9)$ and ASO $(n=7)$ in the case of ducts of a diameter longer than or equal to $3 \mathrm{~mm}$ and with coils in the case of ducts of a diameter shorter than $3 \mathrm{~mm}(\mathrm{n}=6)$. Patent ductus arteriosus type $C$ has been recently treated with symmetrical double-disc nitinol wire mesh occluders (ADO II and ADO II AS) or with VSD occluders in patients with mPAP above $40 \mathrm{~mm} \mathrm{Hg}$. Patent ductus arteriosus types D and $\mathrm{E}$, as well as postsurgical residual shunt or recanalizations, were covered almost completely with coils and ADO II AS. Fluoroscopy time was shorter in procedures using the arterial approach (mainly coils and ADO II AS) as compared with the venous delivery approach (median time, 4 vs 6 min, respectively; $P<0.001$ ) (Supplementary material, Figure $S 2$ ). Over time, a reduction in fluoroscopy time was noted (Supplementary material, Figure S3).

Success rate The procedure was successful in 1021 out of 1036 study patients (98.6\%). There were 3 unsuccessful implantations of RD due to an unstable position of the device $(n=2)$ or its embolization $(\mathrm{n}=1)$. Coil implantation failed in 8 patients due to an unstable position $(n=1)$, protrusion risk $(n=1)$, or device embolization $(n=6)$. There were also a $5-\mathrm{kg}$ patient with a $3.2-\mathrm{mm}$ diameter PDA type A, in whom neither ADO II AS nor DO I implantation were successful, a $4.5-\mathrm{kg}$ patient with a 4-mm diameter PDA type $C$, in whom the procedure was abandoned because of the duct morphology, an 8.9-kg patient with a 1.5-mm diameter PDA type E, in whom crossing the duct with a guidewire resulted in left pulmonary artery wall dissection with the creation of a transient and hemodynamically insignificant pseudoaneurysm, and a single patient with a 1-mm diameter PDA type E, which could not be crossed with a guidewire; both latter ducts closed spontaneously.

Complications Overall, there were 73 periprocedural complications (7\%), of which only 2 (0.2\%) were major and both resulted from device protrusion. A 7-kg patient with a 6-mm diameter PDA type $C$ and mPAP of $65 \mathrm{~mm} \mathrm{Hg}$ developed a moderate left pulmonary artery stenosis after an 8-mm VSD occluder deployment; after 5-year follow-up, he underwent stent implantation to the narrowed vessel. The second 11-kg patient with a 2-mm wide and 5-mm long PDA type E needed urgent surgery due to severe stenosis of the descending aorta with a $3 \times 6 \mathrm{~mm}$ ADO II, as it could not be removed. Most minor complications were access-related ( $n=52)$; the most frequent ones included the need for heparin infusion to restore peripheral pedal pulse $(n=26)$ and 


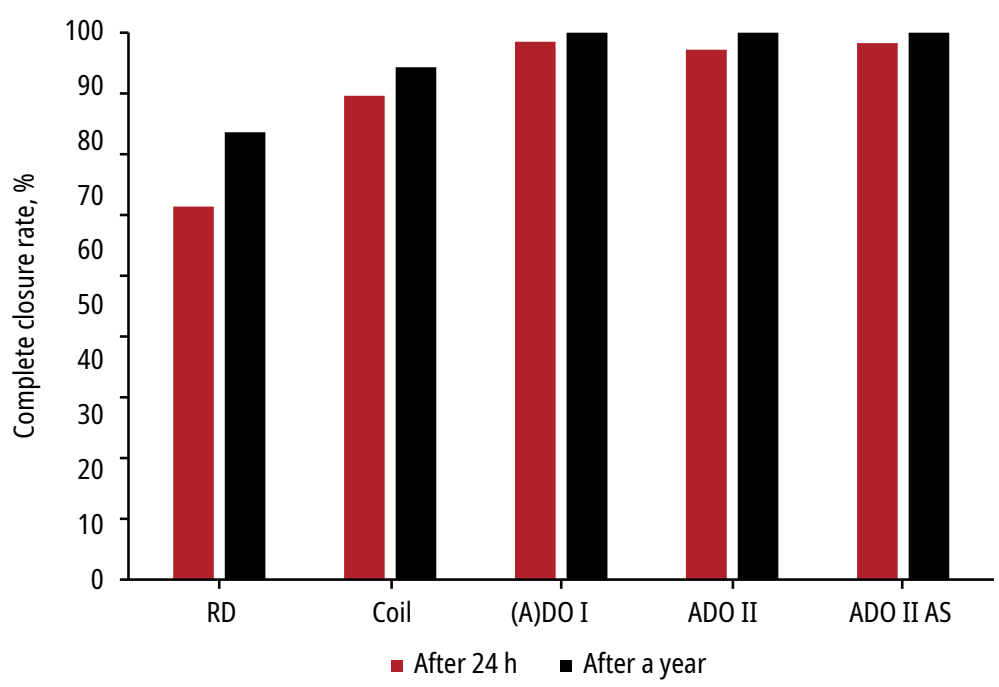

FIGURE 3 Complete patent ductus arteriosus closure rates for selected devices after 24 hours $(P<0.001)$ and a year $(P<0.001)$ (assessed by echocardiography)

Abbreviations: see FIGURE 1
DISCUSSION The Rashkind device was the first commonly used implant for PDA closure and it was used in 25 of our study patients (2.4\%). The device required the use of an 8-11 French venous sheath; however, its successful implantation in even 3.5 -kg infants was reported. ${ }^{17}$ The smallest patient in whom we used RD was a 4-kg infant, but the procedure was unsuccessful owing to device instability. In our analysis, RD had low success and complete closure rates ( $88 \%$ and $81.8 \%$, respectively). Moreover, 3 out of 22 patients with RDs needed subsequent percutaneous closure of residual shunt.

Coils are feasible and safe to occlude small PDA (shorter than $2 \mathrm{~mm}$ ) and can be implanted from both sides and only through 4 French catheters. Their use in larger ducts is associated with persistent residual shunting and higher embolization rates. ${ }^{13,18}$ We used detachable coils in 451 patients. They presented high success but rather low complete closure rates $(98.2 \%$ and $93.7 \%$, respectively). A total of 10 embolizations were noted (2.2\%). At the beginning (before 2000), due to the lack of alternative devices, simultaneous multiple (double) coils were also used in ducts exceeding $3 \mathrm{~mm}$. Nevertheless, a residual shunting rate greater than $10 \%$ at 1 -year follow-up was observed. With time, we used coils less frequently and only in smaller PDA, which resulted in a decrease in the rate of embolizations to $0.8 \%$ and of residual shunting at 1-year follow-up to $2.4 \%$ in the last 10 years $(n=127)$.

Amplatzer Duct Occluder type I, designed to close PDA in patients weighing more than $6 \mathrm{~kg}$ and older than 6 months, has become a perfect tool to close larger PDAs, especially PDA type A. Numerous devices resembling the original DO I (copies) have been introduced so far and they are frequently available in larger sizes. Overall, we used 159 Amplatzer and 141 Chinese DO I with success rates of $100 \%$ and $99.3 \%$ (a single unsuccessful implantation of Hyperion DO I), respectively. No residual shunting was observed in any of those groups at follow-up. Similar enhancement was reported in other studies. .,19-21 $^{2}$ There were also no differences regarding patients' age, weight, implanted device size, and complication rates between Amplatzer and Chinese DO I groups (Supplementary material, Table S2). Chinese DO I devices have been predominantly used in recent years; therefore, shorter fluoroscopy time with their use can be partially explained by the learning curve.

To our best knowledge, such a comparison of devices used for transcatheter PDA closure has not been reported so far in a similar number of patients.

Both ADO II and ADO II AS represent the next generation of Amplatzer devices. Their symmetrical design with 2 retention discs and flexible structure make them suitable for only a 4-5 French delivery catheter and permits implantation by using either a venous or an arterial approach. 
Of note, ADO II is preferred in small-to-moderate ducts, especially type $C$, and is associated with satisfactory outcomes. ${ }^{22}$ Due to the diameter of the ADO II disc, its use is advised in patients with a descending aorta diameter exceeding $10 \mathrm{~mm}$, as it often protrudes to either the aorta or the left pulmonary artery. ${ }^{23}$ We found this type of complication in a single 11-kg patient (3.1\%), in whom an excessively long ADO II caused a severe stenosis of the descending aorta.

Special attention should be paid to elderly patients with often calcified and fragile ducts, in whom a considerably stiff sheath introduced using a venous approach can be troublesome. ${ }^{24}$ In those patients, devices with symmetrical and articulating retention discs are preferred, such as ADO II and AVP II, which we described elsewhere in detail. ${ }^{25}$

The ADO II AS was designed to close small ducts: 4-mm wide or narrower as well as 8-mm long or shorter ones in smaller children. The ADO II AS discs, which are only 1 to $1.5 \mathrm{~mm}$ larger than the stenting central waist, prevent device protrusion. ${ }^{26}$ We did not note any protrusion or embolization of that device among 209 procedures. The ADO II AS central waist diameter was selected to be median (IQR) 2.9 (1.4-5) times larger than the narrowest PDA diameter. The ADO II AS (also under the name Piccolo) has been currently more frequently used even in premature infants weighing more than $700 \mathrm{~g}$ and has shown good results. ${ }^{27}$ Surgical PDA closure of infants weighing less than $750 \mathrm{~g}$ is still associated with a high early mortality rate. ${ }^{28}$ In the population presented in this study, ADO II AS was also applied in older children and a few adult patients, which was described elsewhere. ${ }^{29}$ Interestingly, there were no differences between ADO II AS and other nitinol devices regarding patients' age or weight. According to Mahmoud et al, ${ }^{26}$ to prevent device protrusion, ADO II AS can be selected in such a way that their length is much shorter than that of the duct. It simultaneously enables its use in ducts longer than $8 \mathrm{~mm}(26.3 \%$ of our patients treated with ADO II AS had such PDA morphology). Moreover, in a few patients with PDA types D and E, ADO II AS was implanted with the aortic retention disc deployed into the duct and not in the ampulla, with no complications or residual shunt. Although generally contraindicated, the application of a short ADO II AS in PDA type B and off-label device use in the aortopulmonary window in an infant have been described. ${ }^{26,30}$

Since the introduction of ADO II AS, it has replaced coils and become our preferred device to close small-to-moderate PDA. This tendency was also reported by other authors. ${ }^{31}$ Coils present a significant residual leak rate, and embolizations are relatively common; however, they are significantly less expensive. ${ }^{32}$ Nowadays, in our center, coil application is limited to PDA type
$\mathrm{D}$ and $\mathrm{E}$ of a diameter shorter than $1.5 \mathrm{~mm}$, in which crossing with a 4 French catheter can be difficult. In those rare cases, we implant the coil in the so-called wedge catheter position.

In special situations, we used off-label devices $(n=17)$. All these procedures were successful. The AVP II was used in 4 patients, mostly in PDA type $\mathrm{D}(\mathrm{n}=3)$. The ASO was applied in 7 patients with PDA type $B$ that was more than $3 \mathrm{~mm}$ wide. For that type of PDA, septal occluders are considered to be safe and effective. ${ }^{9,33}$ The lack of narrowing in PDA type $C$ often results in significant shunting and, therefore, in substantial pulmonary pressure elevation. To avoid embolization, devices with a double retention disc (such as VSD occluders) are preferable. ${ }^{10,34}$

The main limitations of this study include its retrospective, single-center design and the variety of devices available throughout the analyzed time period.

Conclusions The armamentarium for transcatheter PDA closure has greatly developed over the last 25 years. The application of nitinol-based devices, such as Amplatzer duct occluders (of all types), provides excellent results at periprocedural and 1-year follow-up, without residual shunting at 1-month follow-up. Amplatzer devices are feasible and safe in all PDA types. Original Amplatzer DO I and Amplatzer-like copies offer similar results. The ADO II AS has proven its superiority over coils in terms of both safety and the complete closure rate and has become the preferred device to close small-to-moderate PDA.

\section{SUPPLEMENTARY MATERIAL}

Supplementary material is available at www.mp.pl/kardiologiapolska.

\section{ARTICLE INFORMATION}

ACKNOWLEDGMENTS This work was supported by Medical University of Silesia (grant no. KNW-2-K15/D/8/N; to MG).

CONFLICT OF INTEREST None declared.

OPEN ACCESS This is an Open Access article distributed under the terms of the Creative Commons Attribution-NonCommercial-NoDerivatives $4.0 \mathrm{In}$ ternational License (CC BY-NC-ND 4.0), allowing third parties to download articles and share them with others, provided the original work is properly cited, not changed in any way, distributed under the same license, and used for noncommercial purposes only. For commercial use, please contact the journal office at kardiologiapolska@ptkardio.pl.

HOW TO CITE Gałeczka M, Szkutnik M, Białkowski J, et al. Transcatheter patent ductus arteriosus closure: what have we learned after over 25 years? A single-center experience with 1036 patients. Kardiol Pol. 2021; 79: 287-293. doi:10.33963/KP.15812

\section{REFERENCES}

1 Lloyd TR, Beekman RH. Clinically silent patent ductus arteriosus. Am Heart J. 1994; 127: 1664-1665.

2 Porstmann W, Hieronymi K, Wierny L, Warnke H. Nonsurgical closure of oversized patent ductus arteriosus with pulmonary hypertension. Report of a case. Circulation. 1974; 50: 376-381.

3 Rashkind W], Mullins CE, Hellenbrand WE, Tait MA. Nonsurgical closure of patent ductus arteriosus: clinical application of the Rashkind PDA Occluder System. Circulation. 1987; 75: 583-592.

4 Cambier PA, Kirby WC, Wortham DC, Moore JW. Percutaneous closure of the small $(<2.5 \mathrm{~mm})$ patent ductus arteriosus using coil embolization. Am J Cardiol. 1992; 69: 815-816. 
5 Masura J, Walsh KP, Thanopoulous B, et al. Catheter closure of moderate- to large-sized patent ductus arteriosus using the new Amplatzer duct occluder: immediate and short-term results. J Am Coll Cardiol. 1998; 31: 878-882.

6 Thanopoulos B, Eleftherakis N, Tzannos K, Stefanadis C. Transcatheter closure of the patent ductus arteriosus using the new Amplatzer duct occluder: initial clinical applications in children. Am Heart J. 2008; 156: 917.e1-917.e6.

7 Agnoletti G, Marini D, Villar AM, et al. Closure of the patent ductus arteriosus with the new duct occluder II additional sizes device. Catheter Cardiovasc Interv. 2012; 79: 1169-1174.

8 Sathanandam SK, Gutfinger D, O'Brien L, et al. Amplatzer Piccolo Occluder clinical trial for percutaneous closure of the patent ductus arteriosus in patients $\geq 700$ grams. Catheter Cardiovasc Interv. 2020; 96: 1266-1276.

9 Amoozgar H, Salehi S, Farhadi P, et al. Follow-up results of device occlusion of patent ductus arteriosus. Iran J Pediatr. 2016; 26: e3621.

10 Kusa J, Szkutnik M, Bialkowski J. Percutaneous closure of persistent ductus arteriosus with pulmonary hypertension in child weighting $7.7 \mathrm{~kg}$ using Amplatzer Muscular VSD Occluder. Adv Interv Cardiol. 2008; 4: 122-124.

11 Zahn EM, Peck D, Phillips A, et al. Transcatheter closure of patent ductus arteriosus in extremely premature newborns: early results and midterm follow-up. JACC Cardiovasc Interv. 2016; 9: 2429-2437.

12 Baruteau A-E, Hascoët S, Baruteau J, et al. Transcatheter closure of patent ductus arteriosus: past, present and future. Arch Cardiovasc Dis. 2014; 107: $122-132$.

13 Ghasemi A, Pandya S, Reddy SV, et al. Transcatheter closure of patent ductus arteriosus - what is the best device? Catheter Cardiovasc Interv. 2010; 76: 687-695.

14 Kusa J, Szkutnik M, Czerpak B, Bialkowski J. Percutaneous closure of previously surgical treated arterial ducts. EuroIntervention. 2008; 3: 584-587.

15 Krichenko A, Benson LN, Burrows P, et al. Angiographic classification of the isolated, persistently patent ductus arteriosus and implications for percutaneous catheter occlusion. Am J Cardiol. 1989; 63: 877-880.

16 Kusa J, Szkutnik M, Baranowski J, et al. Percutaneous closure of recanalised ductus arteriosus - a single-centre experience. Kardiol Pol. 2007; 65: 125-131.

17 Rashkind W], Cuaso CC. Transcatheter closure of patent ductus arteriosus. Pediatr Cardiol. 1979; 1: 3-7.

18 Tometzki AJ, Arnold R, Peart I, et al. Transcatheter occlusion of the patent ductus arteriosus with Cook detachable coils. Heart. 1996; 76: 531-535.

19 Sinha SK, Razi M, Pandey RN, et al. Prospective evaluation of the feasibility, safety, and efficacy of Cocoon Duct Occluder for transcatheter closure of large patent ductus arteriosus: a single-center study with short- and medium-term follow-up results. Anatol J Cardiol. 2017; 18: 321-327.

20 Santoro G, Giordano M, Gaio G, et al. Transcatheter closure of arterial duct in infants <6 kg: Amplatzer Duct Occluder Type I vs Amplatzer Duct Occluder II additional sizes. Pediatr Cardiol. 2018; 39: 627-632.

21 Bialkowski J, Glowacki J, Zabal C, et al. Patent ductus arteriosus at low and high altitudes: anatomical and haemodynamic features and their implications for transcatheter closure. Kardiol Pol. 2011; 69: 431-436.

22 Liddy S, Oslizlok P, Walsh KP. Comparison of the results of transcatheter closure of patent ductus arteriosus with newer Amplatzer devices. Catheter Cardiovasc Interv. 2013; 82: 253-259.

23 Saliba Z, El-Rassi I, Abi-Warde MT, et al. The Amplatzer Duct Occluder II: a new device for percutaneous ductus arteriosus closure. I Interv Cardiol. 2009; 22: 496-502.

24 Gu X, Zhang Q, Sun H, et al. Transcatheter closure of calcified patent ductus arteriosus in older adult patients: immediate and 12-month follow-up results. Congenit Heart Dis. 2017; 12: 289-293.

25 Galeczka M, Szkutnik M, Bialkowski J, et al. Transcatheter closure of patent ductus arteriosus in elderly patients: initial and one-year follow-up results - do we have the proper device? J Interv Cardiol. 2020; 2020: 1-8.

26 Mahmoud HT, Santoro G, Gaio G, et al. Single-center experience in percutaneous closure of arterial duct with Amplatzer Duct Occluder II additional sizes. Catheter Cardiovasc Interv. 2017; 89: 1045-1050.

27 Sungur M, Karakurt C, Ozbarlas N, Baspinar 0. Closure of patent ductus arteriosus in children, small infants, and premature babies with Amplatzer Duct $0 \mathrm{c}$ cluder II additional sizes: multicenter study. Catheter Cardiovasc Interv. 2013; 82: 245-252.

28 Stankowski T, Aboul-Hassan S, Fritzsche D, et al. Surgical closure of patent ductus arteriosus in extremely low birth weight infants weighing less than 750 grams. Kardiol Pol. 2018; 76: 750-754.

29 Fiszer R, Chojnicki M, Szkutnik M, et al. Are the AMPLATZER Duct Occluder II Additional Sizes devices dedicated only for smaller children? EuroIntervention. 2017; 12: 2100-2103.

30 Fiszer R, Zbronski K, Szkutnik M. Percutaneous closure of an aortopulmonary window using Amplatzer Duct Occluder II: Additional Sizes: the first reported case. Cardiol Young. 2017; 27: 812-815.

31 Sheridan BJ, Ward C], Anderson BW, Justo RN. Transcatheter closure of the patent ductus arteriosus: an intention to treat analysis. Heart Lung Circ. 2013; 22: 428-432.
32 Bruckheimer E, Godfrey M, Dagan T, et al. The Amplatzer Duct Occluder II Additional Sizes device for transcatheter PDA closure: initial experience. Catheter Cardiovasc Interv. 2014; 83: 1097-1101.

33 Bialkowski J, Szkutnik M, Kusa J, Stein J. Percutaneous closure of window-type patent ductus arteriosus using the CardioSEAL $\circledast$ and STARFlex ${ }^{\circledR}$ devices. Tex Heart Inst J. 2003; 30: 236-239.

34 Zabal C, García-Montes JA, Buendía-Hernández A, et al. Percutaneous closure of hypertensive ductus arteriosus. Heart. 2010; 96: 625-629. 